\title{
Immediate effect of trataka on blood pressure indices in individuals with primary hypertension - a randomized controlled trial
}

\author{
A S Kusuma, Nandeesh N S, Shivaprasad Shetty, Prashanth Shetty \\ SDM College of Naturopathy and Yogic Sciences, Ujire, Belthangady Taluk, Dakshina Kannada, India
}

\begin{abstract}
Background and Objectives: Hypertension control remains a major global challenge. Behavioral approaches recommended for blood pressure (BP) reduction include: stress reduction, increased exercise and healthy dietary habits. Some study findings suggest that yoga exerts beneficial cardiovascular effects including blood pressure alterations. This study was done to assess the effect of trataka, a yogic cleansing technique, on blood pressure and heart rate variables in patients with hypertension and thereby substantiate the clinical understanding of its effect on blood pressure. Material and methods: A total of 60 subjects with primary hypertension (age 25-45 years) were randomized to the study. The yoga group practiced trataka for 30 minutes with guided instructions and the control group was asked to sit calmly for 30 minutes. Blood pressure and heart rate were recorded before and after the practice.

Results: The individuals who practiced trataka showed significant reduction in systolic blood pressure (SBP) $(\mathrm{p}<0.05)$, mean heart rate $(\mathrm{HR})(\mathrm{p}<0.05)$, and mean RR $(\mathrm{p}<0.05)$ after the procedure. There were no significant changes observed in the control group as compared to the yoga group.

Conclusion: The practice of trataka leads to significant reduction in blood pressure and heart rate in patients with primary hypertensive. Though trataka is considered as a cleansing technique, it induces calmness similar to a mental state during meditation. Evidently, both techniques bear the potential to reduce stress and, henceforth, blood pressure and heart rate.
\end{abstract}

Key words: trataka; yoga; hypertension; blood pressure; heart rate variability; yogic visual technique

Arterial Hypertens. 2021, vol. 25, no. 2, pages: 82-87

DOI: $10.5603 /$ AH.a2021.0013

\section{Introduction}

Hypertension (HTN) is linked to $57 \%$ of all stroke deaths and $24 \%$ of all coronary heart disease deaths in India [1-3].

Prevention and management of HTN is a global public health challenge. The Eighth Joint National Committee (JNC) guidelines mention lifestyle modifications as the first step in the management of hypertension which is combined with pharma- cotherapy in most cases [4]. The life-style modifications include dietary changes (enhanced intake of vegetables, fruit and whole grains including legumes and restriction of salt, sugars, sugar-sweetened beverages, red meats, trans-fats, alcohol and smoking) and increased structured and repetitive modest physical activity [5].

Yoga is a philosophical, cultural and social legacy of ancient India. It holds the potential to counteract stress-induced physiological changes. Around $10^{\text {th }}$

Address for correspondence: Kusuma A S, SDM College Of Naturopathy And Yogic Sciences, Ujire, Belthangady Taluk, Dakshina Kannada District, 574240 Dakshina Kannada, India, tel: (+91) 7760830357; e-mail: askusuma06@gmail.com 
Century, Sage Swatmarama wrote a text called Hatha Yoga Pradipika in which he explains the methodology of yoga techniques. It includes shatkarmas, asanas, pranayamas, mudras and bandhas. Among these shatkarmas there are six cleansing techniques (kriyas) viz., dhauti, basti, neti, trataka, nauli and kapalabhati, to purify the body [6].

Trataka is fundamentally a concentration method in both Yogic and Tantric regimes as well as in the upanishads. It is also known as Hatha-Yoga-Kriya's-Trataka [7]. The meaning of trataka is "to gaze steadily". The idea of trataka is to look intently at a small object to the moment the tears are shed [6]. Trataka is also another method of meditation involving alternately gazing at an object or point without blinking, then closing the eyes and visualizing the object. Hatha Yoga Pradipika mentions that practice of trataka eradicates fatigue and lethargy [8]. Though trataka is considered as cleansing technique, the final stage of trataka leads to meditative mental state [1].
The present study is conducted to test the immediate cardiovascular effects of trataka in patients diagnosed with primary hypertension.

\section{Material and methods}

The Institutional Ethical Committee of SDM College of Naturopathy and Yogic sciences accepted the protocol of this study. Participants were recruited from the Outpatient and Inpatient facilities of the Sri Dharmasthala Manjunatheshwara Yoga and Nature Cure Hospital. Primary hypertensive patients (as per the JNC VII guidelines) aged between 25 and 45 years were included in this study. Sixty patients (sample size estimation was calculated using $\mathrm{G}^{*}$ power 3.1 .9 , considering $80 \%$ power, $5 \%$ level of significance, 0.5 effect size and a 1:1 allocation ratio, it was found to be 64 for two groups) of both sexes were recruited. The exclusion criteria were

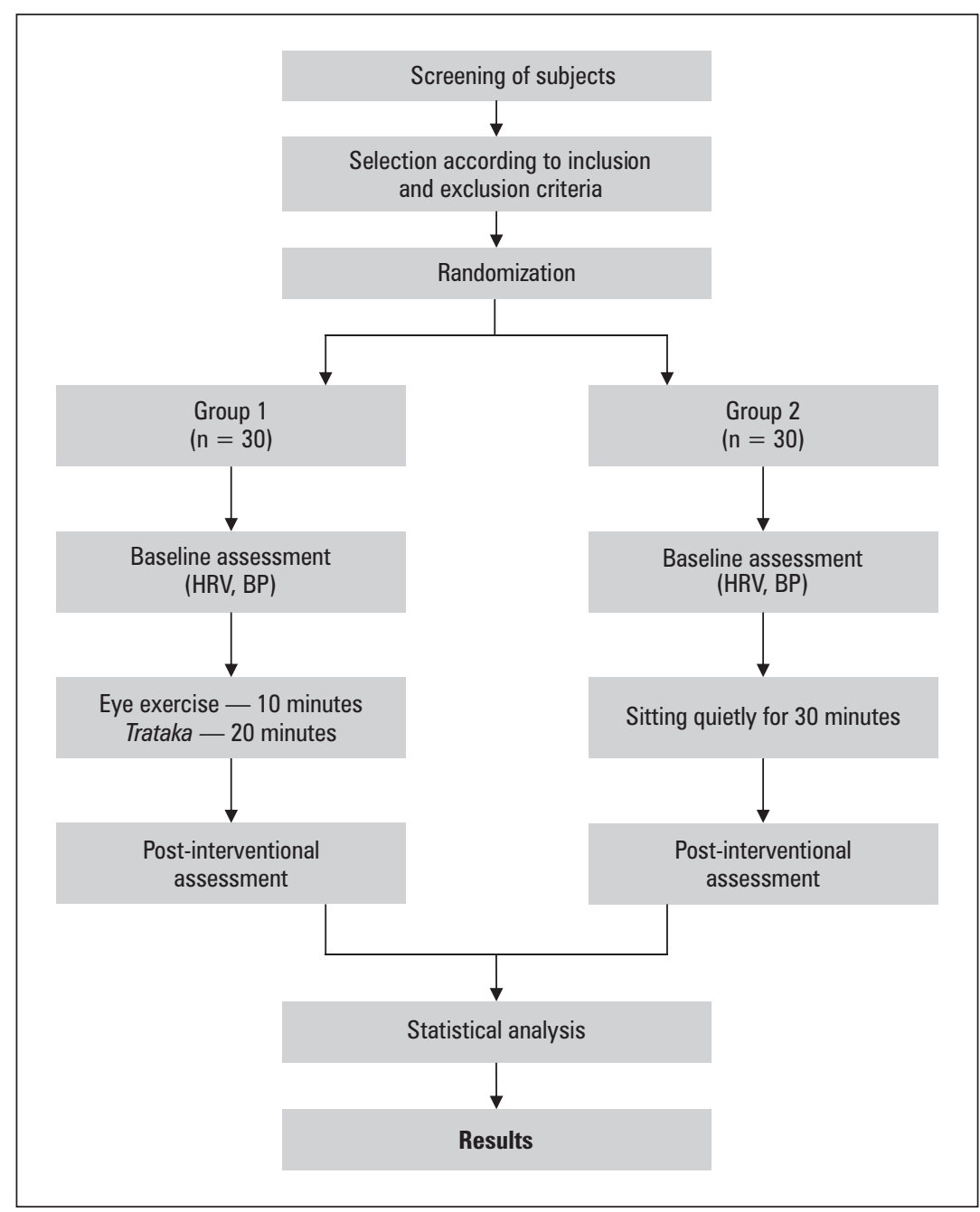

Figure 1. Illustration of the study plan. HRV — heart rate variability; BP — blood pressure 
as follows: history of secondary hypertension, history/signs and symptoms/laboratory results suggestive for kidney, neurologic, and eye complications. Patients were instructed about study objectives, methods (planned procedures) and all the rights of the subject pertaining to the conduction of the study. A signed informed consent was obtained from each subject before the commencement of the intervention.

All procedures were performed at the Research Lab, SDM Yoga and Nature Cure Hospital Shantivana. Subjects were randomly allocated to either experimental or control group by using chit method. Baseline assessment was done for both experimental and control groups. Subjects from the experimental group received detailed instructions and guidance how to properly practice trataka for a period of 30 minutes; controls were asked to sit still for $30 \mathrm{~min}$ utes. After 30 minutes both yoga and the control groups were reassessed.

Heart rate variability (HRV) was recorded for 5 minutes, before and after the intervention, performed by a trained operator. The blood pressure was recorded with an automated device [9]. The HRV spectrum is considered an indicator of both cardiac sympathetic and parasympathetic activities (reflected by low frequency [LF] band power values; and by high frequency $[\mathrm{HF}]$ band power values; respectively) [10]. Data analysis was done using Statistical Package for Social Sciences (SPSS 20.00). Individual group comparisons at baseline and after intervention were done by unpaired t test or Mann-Whitney U test. Categorical variables (proportions) were computed using Fischer's exact test. A probability (p) value $<0.05$ is considered significant.

\section{Statistical analysis}

The data were tested for normality by using Kolmogorov-Smirnov test. The pre and post data of group 1 and group 2 under normal distribution (SBP, DBP, mean RR, mean HR, VLF, LF, HF) were analyzed separately using unpaired $t$ test and parameters that did not follow normal distribution (pretest and posttest scores of RMSSD, NN50, PNN50 and $\mathrm{LF} / \mathrm{HF}$ ) were analyzed by using non parametric tests i.e. Mann-Whitney U test.

\section{Results}

The groups were comparable with respect to age, sex distribution and other clinical aspects.

A significant decrease in systolic and diastolic BP in the yoga group was recorded. In contrast, there
Table 1. Baseline characteristics by unpaired t test

\begin{tabular}{|l|c|c|}
\hline & Yoga group & Control group \\
\hline Age & $38.23 \pm 5.42$ & $36.77 \pm 5.99$ \\
\hline Male & $23(76.67)$ & $23(76.67)$ \\
\hline Female & $7(23.33)$ & $7(23.33)$ \\
\hline SBP & $125.0 \pm 20.33$ & $124.26 \pm 16.45$ \\
\hline DBP & $76.13 \pm 13.31$ & $76.93 \pm 9.15$ \\
\hline
\end{tabular}

was no change in the SBP, DBP in the control group (Tab. 1).

Short-term HRV frequency domain measures: The short-term spectral components, namely VLF power, LF power, HF power and LF: HF, showed no significant change in the control group. In the yoga group, there was a trend towards change in VLF power and LF power. Although HF power showed an insignificant increase in the yoga group, the LF:HF ratio showed a decreasing trend at the end of the intervention (Tab. 2).

Both groups showed no significant changes in the following variables (time domain measures): $\mathrm{SDNN}$, RMSSD, NN50, and pNN50 when compared baseline to the study end assessment. However, in the yoga group mean RR interval, mean HR decreased following the intervention which was not the case in the controls (Tab. 2).

\section{Discussion}

In our study we showed that patients who practiced trataka had a significant reduction in systolic BP and HR. Additionally, there were trends in changes in DBP, RMSSD, PNN50, NN50, LF, HF and LF/HF in the study group. None of these changes was evident in the control group.

We showed that trataka intervention was associated with significant decreases in the HR. Kulkarni et al. demonstrated that decreases in the heart rate suggest a parasympathetic overbalance, which facilitates feeling calmness along with better perception of quality of life [12].

There was an inconsistent decrease in BP in patients subjected to trataka. Immediately after intervention there was an evident systolic BP reduction whereas diastolic BP remained intact. A study by Tells $S$ et al. [13] suggested that specific yoga practices (trataka, relaxation) have been found to evoke physiological changes suggestive of "alertful rest". This description was based on a simultaneous decrease in heart rate and oxygen consumption along 
Table 2. Comparison of pre- and post-intervention parameters in the yoga group and the control group

\begin{tabular}{|c|c|c|c|c|c|c|}
\hline & \multicolumn{3}{|c|}{ Yoga group } & \multicolumn{3}{|c|}{ Control group } \\
\hline & pre & post & $p$ value & pre & post & p value \\
\hline SBP & $125.0 \pm 20.30$ & $119.46 \pm 16.9$ & $0.003^{*}$ & $124.26 \pm 16.45$ & $121.20 \pm 26.07$ & 0.391 \\
\hline DBP & $76.13 \pm 13.31$ & $75.0 \pm 9.70$ & 0.474 & $76.93 \pm 9.15$ & $76.26 \pm 9.92$ & 0.563 \\
\hline \multicolumn{7}{|c|}{ Time domain } \\
\hline Mean RR & $740.74 \pm 75.98$ & $821.05 \pm 116.15$ & $0.001^{*}$ & $773.24 \pm 105.82$ & $786.77 \pm 108.85$ & 0.531 \\
\hline Mean HR & $88.16 \pm 11.76$ & $77.33 \pm 9.20$ & $0.001^{*}$ & $84.60 \pm 13.49$ & $81.75 \pm 13.70$ & 0.240 \\
\hline RMSSD & $138.17 \pm 247.20$ & $216.23 \pm 560.65$ & 0.490 & $377.49 \pm 769.26$ & $130.22 \pm 202.12$ & 0.111 \\
\hline NN50 & $42.06 \pm 65.12$ & $45.53 \pm 68.88$ & 0.799 & $69.86 \pm 91.75$ & $61.96 \pm 81.35$ & 0.648 \\
\hline PNN50 & $12.59 \pm 16.51$ & $11.92 \pm 18.93$ & 0.826 & $17.92 \pm 22.70$ & $16.56 \pm 21.44$ & 0.763 \\
\hline \multicolumn{7}{|c|}{ Frequency domain } \\
\hline VLF & $39.54 \pm 18.76$ & $39.54 \pm 18.76$ & 0.829 & $47.51 \pm 25.43$ & $44.36 \pm 23.23$ & 0.442 \\
\hline LF & $50.34 \pm 19.61$ & $53.34 \pm 22.35$ & 0.549 & $52.33 \pm 21.92$ & $53.45 \pm 17.73$ & 0.760 \\
\hline $\mathrm{HF}$ & $47.59 \pm 20.28$ & $42.90 \pm 21.94$ & 0.381 & $44.83 \pm 22.16$ & $43.62 \pm 17.88$ & 0.742 \\
\hline LF/HF ratio & $1.42 \pm 1.30$ & $1.38 \pm 5.73$ & 0.202 & $2.11 \pm 2.44$ & $3.88 \pm 2.03$ & 0.332 \\
\hline
\end{tabular}

${ }^{*}$ Represents significant, $<0.05$ considered has a significant. SD — standard deviation; HR — heart rate; RR — respiratory rate; MEANRR — mean of R-R interval; RMSSD — the square root of the mean squared difference between adjacent N-N intervals; NN50 - consecutive normal sinus (NN) intervals exceeds 50 ms; pNN50 - the fraction of consecutive NN intervals that differ by more than $50 \mathrm{~ms}$; VLF — very low frequency power; LF — low frequency power; HF — high frequency power; LF/HF — low frequency/high frequency ratio; SBP — systolic blood pressure; DBP — diastolic blood pressure

with a reduction in peripheral cutaneous blood flow $[14,15]$. This could be the reason for reduction in blood pressure in current study. A study by Krishna $\mathrm{B} \mathrm{H}$ et al. reported that yoga therapy in addition to standard medical therapy reduces blood pressure, cardiac load, and improves parasympathetic activity in heart failure patients [16]. Reduction in blood pressure indicates a shift in the balancing components of autonomic nervous system towards the parasympathetic activity which was reported by Santha Joseph et al. [17] and Anand BK et al. [18].

We weren't able to show significant changes in LF power with response to trataka practicing. This might result from underpowered study, as other authors reported such changes. LF power is considered an indicator of baroreflex function independent of cardiac sympathetic innervations [6]. Decrease in LF power thus indicates an advantageous increase in baroreflex sensitivity [19].

Nevertheless, we report that an increase in parasympathetic tone denoted by decrease in LF:HF ratio (though not significant) may in fact suggest restoring the sympathovagal balance $[20,21]$.

A study showed that the modulation of autonomic nervous system activity might have been brought about through the conditioning effect of yoga on autonomic functions and mediated through the limbic system and higher areas of central nervous system reported by Selvamurthy et al. [22]. Regular practice of yoga increases the baroreflex sensitivity and decreases the sympathetic tone. Restoring blood pressure to normal levels in patients with essential hypertension was reported by Vijaya Lakshmi et al. [23]. The probable mechanisms behind blood pressure fall in patients with essential hypertension following yoga implementation are an increase in baroreflex sensitivity and decrease in the sympathetic tone [24].

There are three categories of meditation techniques and their EEG patterns recently describes. Namely, (1) focused attention (voluntary, unrelenting attention on the object), (2) open monitoring meditation in which there is nonreactive monitoring of the moment-to-moment content of experience, and (3) automatic self-transcending, which includes techniques intended to transcend their own activity. Trataka includes focused attention, which might be the reason for changes in blood pressure and heart rate variability in current study. Meditation itself alleviates anxiety thus reducing stress, which leads to a decrease in arterial tone and peripheral resistance. Altogether blood pressure fall is evident [25]. This ensures improvement in peripheral circulation, as reported by Bhargava R et al. [26] and Gopal KS et al. [27]. Yoga therapy adjuvant to standard medical hypotensive therapy has been reported to reduce blood pressure and improve parasympathetic activity in heart failure patients [16].

A study by Pushpalata $\mathrm{R}$ et al. showed significant reduction in anxiety level. Our brain has several centers that receive optic nerve signaling to modify our functioning of perception. Through the perception, the centers of the brain that remain dormant for an 
ordinary person are awakened. Trataka relieves eye ailment and affects ajna chakra and brain. According to Indian philosophical system, trataka unlocks the inherent energy of the mind and directs it in the dormant areas of consciousness. Further results of one-pointedness of mind are high will power, improved memory and concentration [28].

According to Vyasji, "meaning of yoga is meditation". It means focusing the mind on one point, which is also a good technique to reduce stress and for a peaceful mind. Trataka is yet another method of meditation which involves alternately gazing at an object or point without blinking, then closing the eyes and visualizing the object in the mind. This phenomenon is associated with gradual relaxing, and resuming energy [29].

Present study showed that practice of trataka had beneficial effects in patients diagnosed with hypertension. A significant reduction in systolic blood pressure and heart rate was evident. To the best of our knowledge, there are no previously published reports on effects of trataka in patients with HTN. Our study is the first to report on these clinical benefits. However, as the study duration was rather short, a longer intervention is merited. We conclude that trataka technique effectively reduces BP in hypertensive patients. Hence we hypothesize that practicing of trataka may help in controlling BP in primary hypertension.

\section{Conclusion}

We showed that trataka appeared to be a simple, non-invasive and free of side-effects means to effectively lower blood pressure and heart rate in patients with hypertension.

\section{Limitations of the study}

Larger sample size would have given more reliable results. Whether the BP lowering effect of trataka practicing sustains over the longer period of time than assessed in our study needs to be determined.

\section{References}

1. Carretero OA, Oparil S. Essential hypertension. Part I: definition and etiology. Circulation. 2000; 101(3): 329-335, doi: 10.1161/01.cir.101.3.329, indexed in Pubmed: 10645931.

2. Gupta V, Rai N, Toppo N, et al. An epidemiological study of prevalence of hypertension and its risk factors among non migratory tribal population of Mawai block of Mandla district of central India. Int J Commun Med Publ Health. 2018; 5(3): 957, doi: 10.18203/2394-6040.ijcmph20180464.

3. Hackam DG, Khan NA, Hemmelgarn BR, et al. Canadian Hypertension Education Program. The 2010 Canadian Hyperten- sion Education Program recommendations for the management of hypertension: part 2 - therapy. Can J Cardiol. 2010; 26(5): 249-258, doi: $10.1016 / \mathrm{s} 0828-282 \times(10) 70379-2$, indexed in Pubmed: 20485689.

4. James PA, Oparil S, Carter BL, et al. 2014 evidence-based guideline for the management of high blood pressure in adults: report from the panel members appointed to the Eighth Joint National Committee (JNC 8). JAMA. 2014; 311(5): 507-520, doi: 10.1001/jama.2013.284427, indexed in Pubmed: 24352797.

5. Eckel RH, Jakicic JM, Ard JD, et al. Americal College of Cardiology, Americal heart Association, American College of Cardiology/American Heart Association Task Force on Practice Guidelines. 2013 AHA/ACC guideline on lifestyle management to reduce cardiovascular risk: a report of the American College of Cardiology/American Heart Association Task Force on Practice Guidelines. J Am Coll Cardiol. 2014; 63(25 Pt B): 2960-2984, doi: 10.1016/j.jacc.2013.11.003, indexed in Pubmed: 24239922.

6. Muktibhodananda S. Hatha yoga pradipika. Publications Trust Yoga, Munger, Bihar, India 2006.

7. Rajpoot PL, Vaishnav P. Effect of Trataka on Anxiety among Adolescents. Int J Psych Behav Sci . 2015 ; 8(12): 4004-4007.

8. Nagaratha R, Nagendra H. Yoga for Promotion of Positive Health. Swami Vivekananda Yoga Prakashana, Bangalore 2000.

9. Telles $S$, Singh N, Balkrishna A. Heart rate variability changes during high frequency yoga breathing and breath awareness. Biopsychosoc Med. 2011; 5: 4, doi: 10.1186/1751-0759-5-4, indexed in Pubmed: 21486495.

10. Zhao $\mathrm{S}$, Xie $\mathrm{L}, \mathrm{Hu} \mathrm{H}$, et al. A study of neonatal swimming (water therapy) applied in clinical obstetrics. J Matern Fetal Neonatal Med. 2005; 17(1): 59-62, doi: 10.1080/14767050400028782, indexed in Pubmed: 15804789.

11. An H, Kulkarni R, Nagarathna R, et al. Measures of heart rate variability in women following a meditation technique. Int $\mathrm{J}$ Yoga. 2010; 3(1): 6-9, doi: 10.4103/0973-6131.66772, indexed in Pubmed: 20948895.

12. Franklin SS. Systolic blood pressure: it's time to take control. Am J Hypertens. 2004; 17(12 Pt 2): 49S-54S, doi: 10.1016/j. amjhyper.2004.08.020, indexed in Pubmed: 15607435.

13. Telles S, Naveen KV, Dash M, et al. Effect of yoga on self-rated visual discomfort in computer users. Head Face Med. 2006; 2: 46, doi: 10.1186/1746-160X-2-46, indexed in Pubmed: 17140457.

14. Hainsworth R. Circulatory responses from lung inflation in anesthetized dogs. Am J Physiol. 1974; 226(2): 247-255, doi: 10.1152/ajplegacy.1974.226.2.247, indexed in Pubmed: 4811178.

15. Anand BK, Chhina GS, Singh B. Some aspects of electroencephalographic studies in Yogis. Electroencephalography Clin Neurophysiol. 1961; 13(3): 452-456, doi: 10.1016/00134694(61)90015-3.

16. Sakakibara M, Takeuchi S, Hayano J. Effect of relaxation training on cardiac parasympathetic tone. Psychophysiology. 1994; 31(3): 223-228, doi: 10.1111/j.1469-8986.1994.tb02210.x, indexed in Pubmed: 8008785.

17. Anand BK. Yoga and medical sciences. Indian J Physiol Pharmacol. 1991; 35(2): 84-87, indexed in Pubmed: 1791050.

18. Rahman F, Pechnik S, Gross D, et al. Low frequency power of heart rate variability reflects baroreflex function, not cardiac sympathetic innervation. Clin Auton Res. 2011; 21(3): 133-141, doi: 10.1007/s10286-010-0098-y, indexed in Pubmed: 21279414.

19. Ganong WF. The autonomic nervous system. Review of Medical Physiology. 22nd edn. New York, McGraw-Hill 200: 223-231.

20. Vyas R, Dikshit N. Effect of meditation on respiratory system, cardiovascular system and lipid profile. Indian J Physiol Pharmacol. 2002; 46(4): 487-491, indexed in Pubmed: 12683226.

21. Briasoulis A, Agarwal V, Messerli F. Alcohol Consumption and the Risk of Hypertension in Men and Women: A Systematic Review and Meta-Analysis. J Clin Hypertens. 2012; 14(11): 792-798, doi: 10.1111/jch.12008, indexed in Pubmed: 23126352.

22. Vijayalakshmi P, Bhavanani AB, Patil A, et al. Modulation of stress induced by isometric handgrip test in hypertensive patients 
following yogic relaxation training. Indian J Physiol Pharmacol. 2004; 48(1): 59-64, indexed in Pubmed: 15270370.

23. Kulkarni V. Hypertension in the elderly. J Assoc Physicians India. 2001; 49: 873-876.

24. Telles S, Naveen KV, Dash M, et al. Effect of yoga on self-rated visual discomfort in computer users. Head Face Med. 2006; 2: 46, doi: 10.1186/1746-160X-2-46, indexed in Pubmed: 17140457.

25. Telles S, Naveen KV, Dash M, et al. Effect of yoga on self-rated visual discomfort in computer users. Head Face Med. 2006; 2: 46, doi: 10.1186/1746-160X-2-46, indexed in Pubmed: 17140457.

26. Gopal KS, Bhatnagar OP, Subramanian N, et al. Effect of yogasanas and pranayamas on blood pressure, pulse rate and some respiratory functions. Indian J Physiol Pharmacol. 1973; 17(3): 273-276, indexed in Pubmed: 4788511.

27. Misra A, Singhal N, Sivakumar B, et al. Nutrition transition in India: secular trends in dietary intake and their relationship to diet-related non-communicable diseases. J Diabetes. 2011; 3(4): 278-292, doi: 10.1111/j.1753-0407.2011.00139.x, indexed in Pubmed: 21649865.

28. Iyengar B. Light on the Yoga Sutras of Patanjali. Philosophy East and West. 1996; 46(2): 291, doi: 10.2307/1399412.

29. Bhadra C, Chatterjee K. Effect of Trataka on blood pressure of college level female students. Int J Yoga Physiother Phys Edu. 2017; 2(5): 32-4. 